Acknowledgments: This study was sponsored by Novartis Pharmaceuticals Corporation, East Hanover, NJ.

Disclosure of Interests: Philip J Mease Grant/research support from: Abbott, Amgen, Biogen Idec, BMS, Celgene Corporation, Eli Lilly, Novartis, Pfizer, Sun Pharmaceutical, UCB - grant/research support, Consultant of: Abbott, Amgen, Biogen Idec, BMS, Celgene Corporation, Eli Lilly, Novartis, Pfizer, Sun Pharmaceutical, UCB - consultant, Speakers bureau: Abbott, Amgen, Biogen Idec, BMS, Eli Lilly, Genentech, Janssen, Pfizer, UCB - speakers bureau, Mohit Kumar Bhutani Employee of: Novartis Healthcare Pvt Ltd, Peter Hur Employee of: Novartis Pharmaceuticals Corporation, Esther Yi Employee of: Novartis Pharmaceuticals Corporation, Nina Kim Employee of: Postdoctoral fellow at the University of Texas at Austin and Baylor Scott and White Health, providing services to Novartis Pharmaceuticals Corporation

DOI: 10.1136/annrheumdis-2020-eular.1469

\section{SAT0386 $\quad$ USEFULNESS OF THE FECAL CALPROTECTIN AS SCREENING TOOL FOR INFLAMMATORY BOWEL DISEASE IN PATIENTS WITH SPONDYLOARTHRITIS AND NO DIGESTIVE SYMPTOMS}

C. Merino Argumánez ${ }^{1}$, M. Espinosa ${ }^{1}$, C. Ramos Giráldez ${ }^{2}$, O. Rusinovich ${ }^{1}$, N. De la Torre ${ }^{1}$, J. Campos Esteban ${ }^{1}$, Y. Gonzalez Lama1, V. Matallana ${ }^{1}$, M. Calvo Moya ${ }^{1}$, B. Ruiz Antorán ${ }^{1}$, I. Vera ${ }^{1}$, G. Vázquez ${ }^{1}$, J. L. Andréu Sánchez ${ }^{1}$, J. Sanz $1{ }^{1}$ Hospital Universitario Puerta de Hierro, Majadahonda, Spain; ${ }^{2}$ Hospital Universitario Virgen de Valme, Sevilla, Spain

Background: Fecal calprotectin (FC) is a biomarker of bowel inflammation widely spread in diagnosis and follow-up of inflammatory bowel disease (IBD). It is classically estimated that $5 \%$ of patients with axial spondyloarthritis ( $\mathrm{SpA})$ also have IBD; coexistence of both conditions has definite impact in clinical decisions. Proactive detection of both diseases should be advisable, though appropriate screening tools are still lacking.

Objectives: To evaluate the usefulness of FC for the diagnosis of IBD in patients diagnosed with SpA with no clinical suggestive manifestations or previous diagnosis of IBD.

Methods: Patients from a Rheumatology clinic diagnosed with SpA who met ASAS criteria and did not present digestive symptoms suggestive of IBD were consecutively included. Demographics, clinical and analytical data of SpA (uveitis, HLA B27, acute phase reactants) at the time of inclusion, and treatment history were collected. Patients with a positive FC (>50 mg/ $\mathrm{Kg})$ underwent ileocolonoscopy with biopsies of colon and terminal ileum. Patients who were recommended to avoid NSAIDs 2-4 weeks before stool collection and endoscopy. Patients with no endoscopic findings underwent a second determination of feca calprotectine. If persisted positive, capsule endoscopy was performed to evaluate small intestine.

Results: 98 patients included; $47 \%$ male, mean age 46.1 (20-74) years. BASDAI $3.6 \pm 2.5$. HLA B27 positive in $78 \%$ of patients, high ESR in $31.6 \%$, high CRP in $9.2 \%$. FC positive in 49 patients (50\%): mean $147 \mathrm{mg} / \mathrm{kg}$ (range $0-3038$ ).

47 underwent ileocolonoscopy: In 13 cases (26.5\%), endoscopic findings were suggestive of IBD (7 Crohn's disease and 1 ulcerative colitis). Microscopic inflammation was found in 2 additional cases. Among those 34 patients with normal ileocolonoscopy, 16 patients refused further investigations; among the remining 18 patients, a second FC was positive in 16. Capsule endoscopy showed findings suggestive of small intestine IBD in 6 additional patients.

In patients with high FC levels, those with high CRP and ESR were more likely

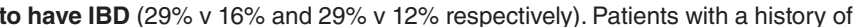
uveitis $(18 \%$ vs $12 \%)$ or psoriasis $(33 \% \vee 16 \%)$ also had a higher prevalence of IBD, although none of those differences reached statistical significance.

FC was higher in smokers $(72 \% v 44 \% ; p=0.03)$. There were no significant differences regarding HLA B27. No statistically significant differences were found in FC between patients with high FC who were diagnosed with IBD and those who were not.

Conclusion: In our study, patients with $\mathrm{SpA}$ and no clinical feature suggestive of IBD who showed $\mathrm{FC}>50 \mathrm{mg} / \mathrm{kg}$ had high prevalence of IBD, which could indicate the usefulness of FC as screening tool for IBD in patients with SpA.

Patients with SpA and other immune-mediated condition or elevated CRP, seem to be more likely to have subclinical IBD.

Disclosure of Interests: None declared

DOI: 10.1136/annrheumdis-2020-eular.5267

\section{SAT0387 \\ ROLE OF HLA-B27 IN THE COMORBIDITIES OBSERVED IN AXIAL SPONDYLOARTHRITIS: DATA FROM COMOSPA}

M. Arévalo ${ }^{1}$, C. López-Medina ${ }^{2}$, M. Moreno ${ }^{1}$, A. Moltó ${ }^{2}$, F. U. Pilar ${ }^{3}$, E. CollantesEstévez ${ }^{3}$, J. Gratacos-Masmitja ${ }^{1} .{ }^{1}$ Parc Taulí Hospital Universitari I3PT,
Rheumatology, Sabadell, Spain; ${ }^{2}$ Hospital Cochin, Paris, France; ${ }^{3}$ Hospital Universitario Reina Sofia, Córdoba, Spain

Background: Comorbidities have merged as an important field in Spondyloarthritis, however there is few data about its relationship to genetic factors such as HLA-B27.

Objectives: To analyze the potential association between the presence of HLAB27 and the different comorbidities observed in axSpA patients.

Methods: A comparative cross-sectional study including axSpA patients from COMOSPA registry. COMOSPA is a worldwide registry that includes a wide set of anthropometric and clinical variables from 3984 patients with spondyloarthritis. The registry also includes the most frequent comorbidities observed in spondyloarthitis such as obesity, hypertension, diabetes, hyperlipidemia, heart ischemic disease, stroke, renal failure, neoplasms, peptic ulcer, diverticulitis, chronic obstructive pulmonary disease, and the presence of osteoporosis. A descriptive analysis and a multiple logistic regression model was performed including all variables assessed.

Results: 2370 patients fulfilled ASAS criteria of axSpA patients and were included in the study. 1858 (78.4\%) of them were HLA-B27 positive. HLA-B27 positive axSpA patients presented significantly higher percentage of male sex, longer disease duration, higher percentage of definite Ankylosing Spondylitis, higher CRP levels, and were also more frequent tobacco consumers and excessive alcohol intakers compared to the negatives. However, disease activity meas ured by BASDAI, BASFI and ASDAS-CRP were all significantly higher in the HLA-B27 negative patients compared to the positive ones.

The only association observed between any comorbidity and presence of gen HLA-B27 was the presence of osteoporosis. This association was independently significant even after adjusting in the multivariate analysis for all variables assessed.

Conclusion: The association observed between the gen HLA-B27 and the presence of osteoporosis in axSpA patients could be of great relevance given the impact of osteoporosis in the phenotypical frame of axSpA patients.

Disclosure of Interests: Marta Arévalo: None declared, Clementina LópezMedina: None declared, Mireia Moreno: None declared, Anna Moltó Grant research support from: Pfizer, UCB, Consultant of: Abbvie, BMS, MSD, Novartis, Pfizer, UCB, Font Ugalde Pilar: None declared, Eduardo Collantes-Estévez Grant/research support from: ROCHE and Pfizer., Speakers bureau: ROCHE, Lilly, Bristol and Celgene., Jordi Gratacos-Masmitja Grant/research support from: a grant from Pfizzer to study implementation of multidisciplinary units to manage PSA in SPAIN, Consultant of: Pfizzer, MSD, ABBVIE, Janssen, Amgen, BMS Novartis, Lilly, Speakers bureau: Pfizzer, MSD, ABBVIE, Janssen, Amgen, BMS Novartis, Lilly

DOI: 10.1136/annrheumdis-2020-eular.2913

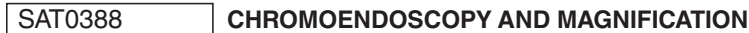 COLONOSCOPY: ANALYSIS OF THE MUCOSA OF THE COLON AND ILEUM IN PATIENTS WITH SPONDYLOARTRHITIS AND GASTROINTESTINAL SYMPTOMS WITHOUT INFLAMMATORY BOWEL DISEASE}

C. Florez ${ }^{1,2}$, V. Parra-Izquierdo ${ }^{1,2}$, W. Bautista-Molano ${ }^{2,3}$, Y. M. ChamorroMelo $^{4}$, A. Beltrán-Ostos ${ }^{5}$, D. Jaimes ${ }^{6}$, J. De Avila $^{2}$, A. Ramos-Casallas ${ }^{2}$, D. Acero-M ${ }^{3}$, J. M. Bello-Gualtero ${ }^{4}$, J. Gutiérrez-Sánchez ${ }^{4}$, C. F. Pacheco Tena $^{7}$, L. Chila ${ }^{2}$, P. Chalem ${ }^{8}$, C. Romero-Sánchez ${ }^{2,4} .{ }^{1}$ Grastroadvanced SAS, Bogotá, Colombia; ${ }^{2}$ Universidad El Bosque, School of Dentistry, Cellular and Immunology Group -INMUBO-, Bogotá, Colombia; ${ }^{3}$ Universidad Militar Nueva Granada, Clinical Immunology Group, Bogotá, Colombia; ${ }^{4}$ Hospital Militar Central, Rheumatology and Immunology Department, School of Medicine, Bogotá, Colombia; ${ }^{5}$ Hospital Militar, Subdirección de docencia e Investigación, Bogotá, Colombia; ${ }^{6}$ Clínicos IPS, Bogotá, Colombia; ${ }^{7}$ Investigación y Biomedicina de Chihuahua, Chihuahua, Mexico; ${ }^{8}$ Instituto de Genética Humana, Facultad de Medicina, Pontificia Universidad Javeriana, Bogotá, Colombia

Background: Digital chromoendoscopy with magnification is a technique that identify microscopic inflammation, with a better characterize, highlighting specific gastrointestinal findings showing a good correlation with histopathological features. Spondyloarthritis (SpA) patients with the presence of non-specific gastrointestinal symptoms, subclinical intestinal inflammation is defined by endoscopic and histological techniques

Objectives: To detect early structural inflammatory changes by chromoendoscopy and magnification colonoscopy in colonic/ileum digestive mucosa and establish its association with clinical variables in patients with SpA and gastrointestinal symptoms 